\title{
0 trabalho do paleontólogo Frederico Waldemar Lange (1911-1988) no Museu Paranaense entre 1941 a $1955^{1}$
}

* Este artigo deve ser referido como segue: Peyerl D., Silva E. A., Bosetti E. P. 2010. 0 trabalho do paleontólogo Frederico Waldemar Lange (1911-1988) no Museu Paranaense entre 1941 a 1955. Terræ Didatica, 6(1):25-30<http://www.ige. unicamp.br/terraedidatica/>

1 Este artigo é 0 texto integral, com acréscimos, do trabalho apresentado no II Simpósio de Pesquisa em Ensino e História de Ciências da Terra e IV Simpósio Nacional "0 Ensino de Geologia no Brasil" (São Paulo - SP, 2009).
Drielli Peyerl

Doutoranda em Ensino e História de Ciências da Terra - UNICAMP

driellipeyerl@gmail.com

Edson Armando Silva

Departamento de História - UEPG

edasilva@uepg.br

Elvio Pinto Bosetti

Departamento de Geociências - UEPG

elvio.bosetti@pesquisador.cnpq.br

\begin{abstract}
The archives of the paleontologist Frederico Waldemar Lange (1911-1988) has been source for many studies related to Geosciences History. The pathway of this self-taught researcher, world-wide known by his scientific work, is deeply related with the 20th century thought. Lange worked on the Museu Paranaense during the years 1941-1955, and his work represents a mark in the History of Brazilian Paleontology. He iniciated his scientific career as an assistant on the geology section, reaching the position of director later. Lange published fourteen papers during this period in the Museu Paranaense, that focused mainly on the devonian fossils of the Paraná State. Until nowadays his work continues to contribute to scientific and historical research.
\end{abstract}

\section{KEYWORDS Archive, History of Geosciences, Museu Paranaense}

RESUMO O arquivo do paleontólogo Frederico Waldemar Lange (19111988) tem sido fonte de muitos estudos relacionados à história das Geociências. O caminho trilhado por este pesquisador autodidata, reconhecido mundialmente por seu trabalho científico, está profundamente relacionado com o pensamento vigente no século XX. Lange trabalhou no Museu Paranaense durante os anos de 1941 até 1955, e suas pesquisas representam um marco na História da Paleontologia brasileira. Ele iniciou sua carreira científica como assistente da Seção de Geologia e chegou a exercer mais tarde o cargo de Diretor. Lange publicou quatorze trabalhos durante este período no Museu Paranaense, trabalhos que enfocavam principalmente os fósseis devonianos do Estado do Paraná. Até hoje seu trabalho continua a contribuir para pesquisas científicas e históricas.

PALAVRAS-CHAVE Acervo, História das Geociências, Museu Paranaense 


\section{Introdução}

O Acervo Frederico Waldemar Lange (19111988) que se encontra sob a guarda e conservação do Laboratório de Paleontologia e Estratigrafia do Departamento de Geociências da Universidade Estadual de Ponta Grossa (UEPG) tem sido objeto de estudos e pesquisas que versam sobre uma impressionante variedade de temas na Geologia, Geografia, Biologia, História, Paleontologia e Micropaleontologia.

O acervo dispõe de vasto material armazenado com o passar dos anos por Frederico Waldemar Lange, o qual se compõe de mapas, relatórios, jornais, coleções conquiliológicas, fotos, cartas, notas de viagens ou de conferências, livros, lâminas com microfósseis, revistas, artigos de diferentes autores e outros de sua própria autoria, e documentos de cunho pessoal.

O trabalho de Lange constituiu um marco na História das Geociências e da Paleontologia brasileira. Neste artigo é esboçado parte do trabalho de Lange no Museu Paranaense, no período de 1941 a 1955, desde quando ele exerceu a função de assistente de Paleontologia e Geologia, até o momento em que assume o cargo de Diretor. Nesse intervalo Lange publicou quatorze das vinte e duas obras escritas de sua trajetória acadêmica.

\section{O Museu Paranaense e o trabalho de Frederico Waldemar Lange}

Inaugurado na cidade de Curitiba em 25 de dezembro de 1876, o Museu Paranaense continha um acervo de 600 amostras, como: artefatos indígenas, moedas, rochas e minerais, insetos, pássaros, borboletas, entre outros objetos. Foi então o primeiro Museu do Paraná e o terceiro do Brasil, sendo o primeiro o Museu Nacional (1818) e o segundo o Museu Paraense (1871), conhecido atualmente como Museu Paraense Emílio Goeldi.

No mesmo período de inauguração, ocorriam mudanças econômicas na produção agrícola do Estado do Paraná, que tinha na erva-mate seu principal produto de exportação, seguida pelo setor madeireiro. Posteriormente, com a implantação das ferrovias, o rápido desenvolvimento da cultura cafeeira no norte do estado e o surto de imigrantes recémchegados modificaram o eixo econômico do estado com a integração das novas fronteiras agrícolas.
Influenciado por tais mudanças econômicas, culturais e sociais que o estado vivenciava, o Museu Paranaense foi adquirindo espaço na sociedade. O ideal da construção histórica local e dos seus saberes era também compartilhado pela sociedade paranaense de sua época:

Incrementado rapidamente, por constantes doações que eram publicadas no jornal local a partir de 1879, o horário de visitas foi ampliado e os problemas de espaço que já se vinham avolumado foram resolvidos com a inauguração de um novo salão. Em 1879, o museu foi reformado ampliado e adquiriram-se novas vitrinas. Assim, quando o imperador o visitou em 22/6/1880, demorando-se por duas horas apreciando "os fósseis, as seções de moluscos e crustáceos, assim como os minerais", ficou bastante satisfeito, embora lamentasse a ausência de um catálogo com a classificação dos objetos expostos.

O museu era uma instituição particular, que contava com o apoio do governo mas era fundamentalmente financiada pela população local. As senhoras de Curitiba, por exemplo, se encarregaram da promoção de loterias para sua manutenção financeira (Lopes 1997, p. 209).

No ano de 1882, o Museu transformou-se em órgão oficial de governo, passando a receber contínuas doações, deixando de ser simples depósito para ser um centro de instrução e pesquisa, e propiciando a vinda de missões científicas para o Paraná. Pois a maioria de instituições científicas, projetos e associações na América Latina, tiveram claro viés nacionalista e a vontade de colocar a ciência a serviço do progresso e da transformação do país (Capel 1993).

A estrutura e condições de financiamento do Museu Paranaense foram uma dificuldade sempre presente em seu desenvolvimento. Assim a mudança de prédio e a ampliação de suas atividades mereceram destaque na imprensa.

Tendo mudado de prédio em 1896 e novamente em 1900, neste último se organizaria em seu pátio interno um pequeno Jardim Zoológico e, em 1901, seria publicado um Guia de suas coleções, que incluía seus aspectos históricos e a classificação sistemática das coleções mineralógicas do museu, realizada por Francisco de Paula Oliveira, então diretor da seção de Geologia do Museu Nacional. Essa seção, que era considerada a mais ampla, seria ainda incrementada em 1908 por uma coleção de fósseis devonianos doada por Eusébio de Paula Oliveira, do Serviço Geológico e Mineralógico do Brasil (Lopes 1997, p. 211). 
A construção material e intelectual de uma instituição, associação ou sociedade muitas vezes está atrelada aos fenômenos urbanos, e estas somente podem crescer em clima social e intelectual adequado. Por isso, o desenvolvimento do Museu Paranaense expressa também o desenvolvimento urbano e cultural concentrado na capital, Curitiba.

O Museu Paranaense foi enriquecido pela história das pesquisas e condições geológicas que o Paraná possui, cercado por intelectuais que desejavam contribuir com seus trabalhos para o desenvolvimento científico. O Museu foi dirigido pelos principais intelectuais paranaenses da época, ligados pelo Movimento Paranista que buscava o estabelecimento de uma identidade paranaense, entre eles Agostinho Ermelino de Leão, Romário Martins e Loureiro Fernandes.

Em 1941, Frederico Waldemar Lange especializa-se em Geologia e Mineralogia pela Universidade do Paraná/Museu Paranaense, e assume o cargo de assistente da Seção Paleontologia do Museu no mesmo ano, onde permanece até 1946.

No Jornal O Dia de 09 de agosto de 1941, a matéria intitulada 'Atos Governamentais' descreve a nomeação dos cidadãos e respectivas funções no Museu Paranaense:

Decretos assinados em 8 de agosto de 1941

DECRETO 11.706

O interventor Federal no Estado do Paraná, sob proposta do Conselho Administrativo do Museu Paranaense, nomeia na forma estabelecida no art. 26 do Regulamento do referido museu, os seguintes cidadãos: Secção de Mineralogia - Geologia e Paleontologia - Frederico W. Lang para exercer, respectivamente, as funções de assistentes das subsecções de Paleontologia; e - Heitor Rodrigues Júnior para exercer as funções de auxiliar-voluntário da sub-secção de Mineralogia. (Jornal O Dia. Atos Governamentais. Curitiba - Sábado, 09 de agosto de 1941, Página 07) ${ }^{1}$.

Em 1944, o Museu Paranaense dividia-se nas seguintes Seções: Zoologia; Antropologia e Etnografia; História; Botânica; Geologia, Mineralogia e Paleontologia; Documentação Fotográfica e Administração (A secretaria, a sala de reunião do Conselho, a biblioteca e outras Seções auxiliares).

Secção de Geologia, Mineralogia e Paleontologia.

1 As citações de jornais foram mantidas na íntegra, os erros ortográficos decorrem da cópia sem modificações.
Por último visitamos a secção de Geologia, Mineralogia e Paleontologia, que está sob a direção do dr. Francisco de Assis Fonseca Filho e conta com o auxílio do snr. Waldemar Lange. A secção como homenagem, tem o nome do dr. Francisco de Paula Oliveira; nessa secção os minérios do Paraná estão em monstruario especial ficando em outros armários minérios de outras regiões do País.

Aí é digno de destaque um mapa do Paraná contendo a localização geográfica das jazidas dos diversos minerais, acompanhado de uma amostra de cada produto extraído e cientificamente estudado. Também nossa atenção foi atraída por um pequeno bloco de ferro metálico obtido na Mira Timbutuva pela redução do limonito de Araras. A parte de fossei, a cargo do dr. Waldemar Lange, oferece aspectos curiosíssimos à apreciação do visitante (Jornal O Dia. Museu Paranaense. Curitiba, 19 de janeiro de 1944).

O trabalho de Lange estava voltado para as descobertas fossilíferas do Paraná, em especial a Paleontologia, Micropaleontologia e História das pesquisas paleontológicas no Estado. Estudos relacionados principalmente ao período Devoniano caracterizam essa fase. Participava também ativamente de sociedades relacionadas ao assunto, como exemplo a Sociedade Brasileira de Geologia (1947), eleito vice-presidente em 1950, 1951, 1956 e 1959, Sociedade Brasileira para o Progresso da Ciência (1951), Society for the Study of Evolution (1952), Society of Systematic Zoology (1952) e American Association for the Advancement of Science (1952).

Em 1947, ocorreu fato marcante para a paleontologia do Estado do Paraná. Nesse ano foram encontrados fósseis de Megatério (Mammalia - Xenarthra), no município de Porto União. A reportagem publicada no Jornal O Dia, intitulada 'Valiosa aquisição para o Museu Paranaense', tem como encarregado da possível escavação o paleontólogo Frederico Waldemar Lange, com a função de analisar o local e da retirada dos fósseis. Embora a transcrição seja longa, o jornal fornece interessante descrição:

Interessados em saber como se deu a descoberta dos referidos restos, interrogamos o nosso entrevistado, a esse respeito, o qual apenas nos pode confiar a primeira notificação enviada pelo diretor da Secção de Geologia e Mineralogia, dr. F. W. Lange, que se acha dirigindo as excavações para a remoção do fóssil, e que atualmente se encontra no Rio de Janeiro onde foi tomar parte nos trabalhos do Congresso Brasileiro de Geologia.

Inicialmente a referida notificação ocupa-se da 
situação da localidade fossilífera que fica a $15 \mathrm{Km}$. a SE de Valões, município de Porto União, proximo á Colonia São Jorge, onde ocorrem duas elevações conhecidas legalmente por Serra Emidia e Serra da Casemira, que se destacam nitidamente do terreno em geral apenas suavemente ondulado. Embora de constituição identica aos demais terrenos da região, pois são formadas pelos folhelhos de cores variegadas da formação do Rio do rasto, devem estas serras a sua conformação alongada á presença de diversos diques de diabásio que atravessam, bem como a um ill que as encobre, tornando-se assim mais resistente à erosão.

Aproximadamente na metade da encosta da Serra da Casemira, do lado norte, ocorrem dois degraus um tanto inclinados, cujas depressões foram ocasionadas por pequenos cursos dagua". Posteriormente descreve a mencionada nota como se deu o achado.

"Desejando aproveitar o pequeno córrego existente neste local, os filhos do Sr. Guilherme Senn, proprietário do terreno, iniciaram a excavação de uma das margens afim de fazerem um tanque para a criação de carpas, quando encontraram alguns fragmentos de ossos pertencentes a um animal de grande porte. Posteriormente foram retirados mais alguns ossos, inclusive um fêmur, segundo informações obtidas, tendo parte do material sido enviado á Divisão de Geologia e Mineralogia, do Ministério da Agricultura, no Rio de Janeiro, que por sua vez avisou a secção de Geologia do Museu Paranaense, ao mesmo tempo gentilmente cedendo o direito da coleta do material".

Foi em princípios de novembro do corrente ano, que o encarregado da sub-secção de paleontologia do Museu Paranaense, sr. Frederico Waldemat Lange, visitou a localidade fossilífera afim de estudar a natureza do fóssil e para verificar a possibilidade da sua remoção; foram nesta ocasião retiradas diversas costelas e uma (ilegível), além de outros fragmentos menores, cujo estudo demonstrou tratar-se do esqueleto fossilizado de um megatério, animal extinto há alguns milhares de anos e cuja forma se aproximava á uma preguiça, de enormes dimensões porém, pois chegava a atingir e em alguns casos 5 metros de comprimento por 2 de altura.

A presença da ossada nesta depressão na encosta da serra faz supor tratar-se de antigo pântano em que o animal pereceu atolado, tendo em seguida seus ossos sido espalhados por outros animais, possivelmente por abutre, visto não mais se encontrarem na sua posição natual, mas sim separados uns dos outro. Posteriormente todo o local foi encoberto por material de ersão transportado pela água, de tal forma que hoje se encontra uma camada de mais de um metro de espessura de terra sobre os despojos. Os osso não etão de todo petrificados, notando-se apenas uma delgada casca em algumas peças, originadas pela infiltração da sílic; de um modo geral os restos estão muito mal conservados, toranndo-se necessario o emprego de colas para juntar e remover os diversos fragmentos.

Dentro de pouco tempo será reiniciado o trabalho afim de ser removido o restante do material, tendose a esperança de ser então encontrada a cabeça do animal. Depois de devidamente preparados, deverão os ossos fósseis ser expostos no Museu Paranaense, cuja diretoria aproveita o ensejoj para agradecer ao sr. Guilherme Senn (bem como aos srsã Teodoro Lemos e Alípio Ortiga) pelo auxilio prestado aos funcionarios do Museu durante o trabalho da remoção. (Jornal O Dia. Valiosa Aquisição para o Museu Paranaense. Curitiba, domingo, 30 de novembro de 1947, $\mathrm{n}^{\mathrm{o}} 7.700$, Ano XXIV).

No mesmo ano da descoberta, Lange torna-se Chefe do Setor de Geologia, onde permanece até 1954. Entre os anos de 1950 e 1955, Lange também atuou como Professor da Faculdade Católica de Filosofia em Curitiba.

Com o trabalho do Museu Paranaense e como professor universitário, entre os anos de 1941 e 1955, Lange publicou quatorze trabalhos: 'Restos vermiformes do Arenito Furnas'. Arquivos Museu Paranaense, 1942; 'Novos fósseis Devonianos do Paraná'. Arquivos Museu Paranaense, 1943; 'Arenitos da Vila Velha'. Museu Paranaense, 1944; 'Novas localidades fossilíferas da Série Itararé'. Anais Academia Brasileira de Ciências XVI, 1944; 'Anelídeos poliquetas dos folhelhos Devonianos do Paraná. Arquivos Museu Paranaense, 1947; Polychaete annelids from the Devonian of Paraná, Brazil (Chitinozoa) Paleont. Research Institution, 1949; 'Novos microfósseis Devonianos do Paraná'. Arquivos Museu Paranaense, 1949; 'Um nôvo escolecodonte dos Folhelhos Ponta Grossa'. Arquivos Museu Paranense, 1950; 'Revisão da fáunula do Folhelho Passinho'. Dusenia, 1952; 'Chitinozoários do folhelho Barreirinha, devoniano do Pará'. Dusenia, 1952; 'Paleontologia e Evolução dos seres vivos', In: Evolução dos Sêres Vivos. Centro de Estudos de História Natural, Faculdade de Filos. Ci. Letras, Universidade do Paraná, 1953; 'Estratigrafia e idade geológica da Série Tubarão’. Arquivos Museu Paranaense, 1954; 
'Paleontologia do Paraná'. Vol. Comemorativo $1^{\circ}$ Centenário do Paraná, 1954; 'Nota preliminar sobre a fáunula do Arenito El Carmen'. Sociedade Brasileira de Geologia, 1955.

O Boletim do Museu Paranaense (1904), único boletim que o Museu conseguiu publicar nesse período, deixou de ser publicado por falta de verbas, mas vale destacar que a circulação em nível mundial de muitas dessas publicações que ocorreram no país estimularam debates, polêmicas, e trocas de informações, oferecendo visibilidade aos trabalhos científicos dos autores. Apenas no ano de 1941, o Museu passa a contar com seus Arquivos do Museu Paranaense (Lopes 1997).

No caso do Museu Paranaense,

O primeiro número de sua revista científica O Boletim do Museu Paranaense - seria publicado em 1904, pela iniciativa do historiador e jornalista Alfredo Romário Martins, que assumira a direção do museu em 1902. O "editorial" do tomo I do Boletim do Museu Paranaense informava que nesses anos o museu reunira grande cópia de exemplares da fauna, da mineralogia, da arqueologia indígena e da etnologia brasileira e que, bem organizado como então estava, procurava seguir e identificava, mesmo que a distância, aos demais museus do país. (Lopes 1997, p. 211).

Grande parte das publicações de Lange estava vinculada aos Arquivos do Museu Paranaense; todas constituem publicações relevantes para as ciências no Brasil. As publicações dentro de instituições, museus, associações e sociedades são fundamentais, principalmente na troca de informações (com outros países e estudiosos do assunto), a divulgação e demonstração das pesquisas e estudos realizados no momento. Porém as dificuldades para criar séries regulares de publicação e para a continuidade destas é característica frequente na América Latina, principalmente nos fins do século XIX e começo do $\mathrm{XX}$, com poucas publicações e grau alarmante de dificuldades financeiras (Capel 1993).

Os trabalhos de Lange o projetaram no cenário científico local e internacional, devido principalmente as suas publicações enquanto atuava no Museu Paranaense. Um de seus trabalhos denominado 'Anelídeos Poliquetos nos Folhelhos do Devonivano do Paraná', publicado nos Arquivos do Museu Paranaense, em 1947, foi internacionalmente reconhecido. Algumas notas em jornais locais relataram o ocorri- do. O Jornal Gazeta do Povo - Paraná, de 29 de abril de 1949, na seção 'Vida Científica', destaca o fato e elogios ao ilustre paleontólogo Frederico Waldemar Lange, com a menção a honrosa apreciação do Journal of Paleontology sobre o trabalho de Lange.

No ano passado os "ARQUIVOS DO MUSEU PARANAENSE", em seu volume sexto, PP. 161-230, publicaram um artigo sobre "Anelídeos poliquetos nos folhelhos devonianos do Paraná" que teve grande repercussão nos meios estrangeiros especializados tendo seu autor, Snr. Frederico Waldemar Lange, de Ponta Grossa, recebido uma solicitação no sentido de que o mesmo artigo fosse traduzido para o inglês e publicado no "Journal of Paleontology", afim de ter maior divulgação dada a sua capital importância para o estudo dos escolecodontes.

O Museu Paranaense, de cuja secção de Paleontologia e Geologia é diretor o Snr. F. W. Lange, acedeu à solicitação concedendo licença para a referida tradução e publicação dando assim todo apôio para que se projete no estrangeiro, era toda sua grandeza, esse notável pesquisador que, trabalhando só e contando apenas com seu esforço e denodo pessoal, chegou a especializar-se notavelmente em alguns grupos de fosseis do devoniano paranaense, que permitirão um melhor estudo comparativo do nosso passado geológico.

Deixamos a palavra ao crítico do artigo, o Prof. Dr. Kenneth E. Caster, da Universidade de Chicago, que em um "Review" aparecido no Journal of Paleontology, assim se expressa sobre o mesmo:

"Esta é provavelmente a mais importante monografia até agora escrita sobre os escolecodontes, sendo, certamente, a mais preciosa destes últimos anos.

Representa ao mesmo tempo significativa contribuição, que até hoje não se tinha elaborado em anos anteriores, ao conhecimento da forma devoniana da America do Sul". (Jornal Gazeta do Povo. Vida Científica. Curitiba, Paraná, sexta-feira, 29 de abril de 1949, Ano XXXI, no 8.613, p. 05).

Neste trabalho, Lange descreve coleção que inclui milhares de espécimes de escolecodontes, cuidadosamente coletados nos folhelhos devonianos de Ponta Grossa. Pelas palavras do Prof. Kenneth E. Caster, na citação acima, ressaltam-se o seu conhecimento e também seus estudos referentes aos fósseis do Devoniano do Paraná.

No ano de 1954, Lange torna-se Diretor do Museu Paranaense, onde permaneceu até 1955. 
Durante sua direção, como podemos observar na publicação do Jornal Diário do Paraná, de 29 de março de 1955, acumulou o cargo de direção da Seção de Geologia:

Em março de 1955, o Museu Paranaense compunha-se de seis secções: "Antropologia e Etnografia, Botânica, Cinema Educativo, Geologia e Paleontologia. História e Zoologia”. A secção de Geologia era dirigida por Frederico Waldemar Lange, o qual também era o atual diretor do Museu, definido no Jornal Diário do Paraná como "geólogo paranaense, que dirige em Ponta Grossa serviços do Conselho Nacional do Petróleo". A freqüência anual estava em torno de 25.000 mil pessoas, sendo que nas segunda e sexta-feiras não se abriram suas portas. (...)

"Um mapa mural apresentando síntese da história geológica do Paraná, com as respectivas legendas ocupa lugar de relevo da secção de Geologia e Paleontologia. Coleções de figuras de fósseis devoneanos, organizadas no século passado por Orvilde Derby e ossos de um megatério, grande mamífero com dimensões de elefante, coletados pelo professor Lange em Valões, formam entre as preciosidades da sala. O megatério, que surgiu no período terciário na América do Sul, de que apenas se conhecem os ossos fósseis, está disposto acima de alguns exemplares répteis do período permiano, encontrado nos folhelhos betuminosos de Irati. Esses répteis têm cerca de 250 milhões de anos.

Há também, uma exposição ampla dos recursos naturais do território, além do mapa mural, mostrando fragmentos geológicos. $\mathrm{Na}$ casa das coisas antigas repousa a glória do Paraná." (Jornal Diário do Paraná, Curitiba, 29 de março de 1955, Ano I, N 1, Página 02).

Em 1955, Lange encerra seu importante trabalho no Museu Paranaense, transferindo-se para a função de paleontólogo na Petrobras. Com a fundação da Petrobras em 1953, e a instalação de um de seus polos regionais em Ponta Grossa, Paraná, em 1955, Lange foi convidado a continuar suas atividades de pesquisa paleontológica na empresa. Começou a ganhar posições funcionais mais elevadas, assumindo, em 1958, a Chefia do Distrito de Exploração da Bacia Sedimentar do Paraná (DEBSP). Mas tarde, foi convidado pelo geólogo norte-americano Walter K. Link a ocupar o cargo de Superintendente-Adjunto do Departamento de Exploração (DEPEX/Petrobras) no Rio de Janeiro, passando, durante os anos de 1961/1962, a exercer a Superintendência Geral do DEPEX, o mais importante cargo na linha exploratória da Petrobras (Peyerl \& Bosetti, 2008).

\section{Considerações Finais}

Este artigo sintetiza a trajetória realizada por Frederico Waldemar Lange (1911-1988) no Museu Paranaense durante os anos de 1941 a 1955. Nascido em Ponta Grossa (situada a 117 km de Curitiba), dedicou sua vida aos estudos da História das Geociências. Além de contribuir para a descoberta, descrição e catalogação de espécimes da Seção de Geologia, Mineralogia e Paleontologia do Museu, divulgou seu trabalho com a publicação de obras que marcaram o desenvolvimento da ciência e lhe proporcionaram reconhecimento nacional e internacional.

\section{Referências}

Capel H. El asociacionismo cientifico em Iberoamerica. La necesidad de un enfoque globalizador. In: Congresso Internacional Ciencia, descubrimiento y mundo colonial, Madri, 2008. Actas..., Madri: Ediciones Doce Calles. 1993.

Jornal Diário do Paraná. 1955. Na casa das coisas antigas repousa a gloria do Paraná. Curitiba, 29 de março de 1955, Ano I, N 1, Página 02.

Jornal Gazeta Do Povo. 1949. Vida Científica. Curitiba, Paraná, sexta-feira, 29 de abril de 1949, Ano XXXI no 8.613, p.05.

Jornal O Dia. 1941. Atos Governamentais. Curitiba: Sábado, 9 de agosto de 1941, p. 07.

Jornal O Dia. 1944. Museu Paranaense. Curitiba, $4^{\text {a }}$ feira, 19 de janeiro de 1944.

Jornal O Dia. 1947. Valiosa Aquisição para o Museu Paranaense. Curitiba, domingo, 30 de novembro de 1947, n 7.700, Ano XXIV.

Lopes M.M. 1997. O Brasil descobre a pesquisa científica. Os museus e as ciências naturais no século XIX. São Paulo: Hucitec.

Peyerl D., Bosetti E.P. 2008. Levantamento dos estudos de paleontologia, cultura material e patrimônio histórico através da trajetória do paleontólogo pontagrossense Frederico Waldemar Lange (1911-1988). In: III Simpósio Paranaense de Pós-Graduação em Geografia, Ponta Grossa, 2008. Anais..., Ponta Grossa. 2008. 